\title{
Perspective
}

\section{Measurement of Brain Metabolites by 'H Magnetic Resonance Spectroscopy in Patients with Schizophrenia: A Systematic Review and Meta-Analysis}

\author{
R Grant Steen*,', Robert M Hamer' and Jeffrey A Lieberman' \\ 'Department of Psychiatry, University of North Carolina at Chapel Hill, Chapel Hill, NC, USA
}

\begin{abstract}
A systematic review of the literature identified 64 published English-language papers that used proton $\left({ }^{1} H\right)$ magnetic resonance spectroscopy to measure $\mathrm{N}$-acetylaspartate (NAA) concurrently in healthy controls and in patients with a diagnosis of schizophrenia (SZ). A total of 1209 controls and 1256 patients have been evaluated, with $88 \%$ of studies carried out at I.5 T field strength, and $77 \%$ of studies focused on patients with chronic SZ. There is consistent evidence that NAA is reduced in a broad range of tissues in the SZ brain. Broad consensus ( $\geqslant 10$ studies) is emerging that NAA levels are reduced $\geqslant 5 \%$ in hippocampus and in both cortical gray matter (GM) and white matter (WM) of the frontal lobe. There is no evidence to support a hypothesis that relative NAA levels are reduced to a different degree in frontal lobe GM and WM, nor is there robust evidence of a difference in NAA levels between patients with firstepisode and chronic SZ. Study reliability may be a problem, as most studies appear to be underpowered. With simple assumptions about the inherent difference in NAA levels between patients and controls, it can be calculated that a minimum sample size of approximately 39 patients and 39 controls is required for acceptable statistical power. Only three of 64 studies included enough subjects to have $80 \%$ power to detect a 10\% NAA reduction in patients, and no studies were adequately powered to detect a $5 \%$ NAA reduction with $80 \%$ power.

Neuropsychopharmacology (2005) 30, 1949-1962. doi:10.1038/sj.npp. I300850; published online 10 August 2005
\end{abstract}

Keywords: first-episode schizophrenia; brain metabolism; $\mathrm{N}$-acetylaspartate

\section{INTRODUCTION}

Proton $\left({ }^{1} \mathrm{H}\right)$ magnetic resonance spectroscopy (MRS) of the human brain in vivo makes it possible to measure the pool size of certain chemical constituents presumed to be metabolically important, including amino acids (eg $\mathrm{N}$ acetylaspartate or NAA), amines, sugars, and bioenergetic metabolites (Martin et al, 2001). The promise inherent to measuring metabolites in the living brain has made MRS methodology very attractive to investigators interested in psychiatric illness. However, it is not yet clear whether the method has sufficient precision and accuracy to detect differences from normal that may be quite subtle in psychiatric patients.

The most abundant metabolite visible by MRS in the healthy human brain is NAA, which is present almost

\footnotetext{
*Correspondence: Professor RG Steen, Department of Psychiatry, Campus Box \#7160, University of North Carolina at Chapel Hill, Chapel Hill, NC, 27599-7I60, USA, Tel: + I 9199668382 ,

E-mail: Grant_Steen@med.unc.edu

Received 15 March 2005; revised 29 April 2005; accepted 17 June 2005

Online publication: 27 June 2005 at http://www.acnp.org/citations/ Npp062705050181/default.pdf
}

exclusively in the nervous system (Birken and Oldendorf, 1989), and which is hypothesized to be a marker of the number of viable neurons (Meyerhoff et al, 1993). Consistent with this hypothesis, levels of NAA in the brain are reduced in a broad range of pathological states, with dramatic reductions seen in patients with tumor or stroke (Zimmerman and Wang 1997; Taylor et al, 1998). Owing to its abundance, NAA can usually be measured with greater precision than any other compound of interest, and many studies have examined NAA levels in the brain of patients with schizophrenia (SZ).

Nevertheless, it is still controversial as to whether brain NAA is reduced in patients with SZ. While some studies have reported a reduction of NAA in certain brain tissues, other studies have failed to replicate such findings or have documented a reduction in other brain tissues, leading to confusion in the literature. To shed light on whether NAA is indeed reduced in patients with SZ, we have systematically reviewed all published English-language reports about NAA in the SZ brain. We also present meta-analyses to determine whether NAA is reduced to an equivalent degree in both gray matter (GM) and white matter (WM), and in both firstepisode (FE) and chronic SZ patients. In addition, we discuss levels of other metabolites in the brain of patients with SZ. 


\section{METHODS}

\section{Study Inclusion and Exclusion Criteria}

Relevant studies of SZ patients were identified in several ways. The primary search used PubMed and the key words 'schizophrenia and spectroscopy and magnetic resonance and brain', in various combinations. The search was limited to articles in English, with abstracts, relating to research in human subjects. This search yielded 169 articles whose abstracts were read, to identify studies that used proton $\left({ }^{1} \mathrm{H}\right)$ MRS on patients with either FE or chronic SZ. All studies that met these broad inclusion criteria were identified as primary references, and the full paper was obtained.

After the primary references were obtained, a secondary search was undertaken, using each of the primary references as a source. The bibliography of each primary reference was searched for additional references that had been missed by the PubMed search. In addition, the bibliographies of several key review articles were searched (Kegeles et al, 1998; Bertolino and Weinberger, 1999; Lyoo and Renshaw, 2002), for papers relating specifically to ${ }^{1} \mathrm{H}$ MRS in SZ patients. Finally, current journals were reviewed to find references too new to have been included in the PubMed search.

Studies are included in the present analysis if brain MRS data were reported for a population of SZ patients and for a population of healthy control subjects evaluated concurrently. Studies were excluded if patients had psychosis without a primary diagnosis of $\mathrm{SZ}$, or if a concurrent control group was not evaluated. We also excluded studies that did not include data on NAA, or did not report data in a format that enabled us to calculate patient metabolite levels as a percentage of control metabolite levels, in an individual brain region.

Data from all eligible studies were entered into a spreadsheet that tabulated study details, including a brief description of the study and the demographics of the study population. Each line of the database tabulated a particular metabolite in a certain brain structure in a specific study (eg NAA in hippocampus in Buckley et al, 1994). Data were also entered summarizing the percent difference in metabolite levels, relative to controls, and whether this difference was statistically significant, according to the analysis presented in the original reference. The final database was 22 columns wide and 155 lines long, and contained approximately 3410 cells.

\section{Data Analysis}

We sought to tabulate NAA levels in a way that would enable us to compare between studies. This meant that we wanted to ignore the units used in individual studies, which can be NAA concentration (usually in arbitrary units) or NAA expressed as a ratio to various other metabolites (eg $\mathrm{NAA}$ /creatine (Cr) or NAA/Cho). We therefore calculated patient NAA levels as a proportion of control NAA levels, irrespective of the units in which NAA was expressed in the original paper, assuming that control NAA levels are comparable across all studies. In most cases, if separate values were reported for each hemisphere, we calculated separate ratios, and then averaged the ratios, since the hypothesis of interest is not related to hemispheric laterality.

Our approach of calculating ratios of patient NAA to concurrently collected control NAA offers the advantage that it should be insensitive to artifacts of the particular data collection parameters used in each individual study. This approach should also be relatively insensitive to partial volume problems that are unique to each study, as long as volumes of interest are placed in equivalent positions in patients and controls. We tested the validity of this approach by comparing NAA levels in various studies of the hippocampus, as a function of the units in which NAA was expressed in the original reference.

We also performed a meta-analysis of the hippocampal data. It is not possible to use proportions in a meta-analysis, since proportions are not normally distributed. Thus, for each component study in the meta-analysis, we abstracted information about sample properties (mean and standard deviation (SD)) from the original paper, and then randomly generated a data set whose sample properties were identical to those reported for each component study. We then pooled all studies and analyzed the pooled data set for significance, using typical parametric statistics.

We then sorted the database by brain structure, to determine where metabolite changes had been sought. Brain metabolite changes in SZ patients are summarized, with respect to controls, on a structure-by-structure basis. We then focused on frontal lobe metabolite levels, to determine whether there is a difference in NAA levels between GM and WM. Finally, we contrasted patients with FE SZ and patients with chronic SZ, by tabulating NAA levels in the prefrontal cortex for both groups.

We did not attempt to do a formal meta-analysis in every case for several reasons. Papers often publish insufficient information to enable one to do a meta-analysis, since some measure of data scatter (SD, standard error (SE)) is required, and such a measure is missing from many papers. In addition, there are several other issues: a meta-analysis requires that many studies use essentially identical patient populations, methods, and end points, which is often not the case in MRS studies of the brain; publication bias (the tendency not to publish negative or nonsignificant results) can be an unseen but intractable problem; and multiple published studies often seem to be derived from overlapping sets of subjects, which would lead to an artifactually high $p$-value, if the effect size were calculated.

In our final analysis, we summarized the coefficient of variation $(\mathrm{CV})$ in all studies that measured NAA levels in frontal lobe, to address the question of whether studies were adequately powered to detect a difference between patients and controls. The NQuery Advisor program (SAS) was used to calculate the power of each individual study to detect an effect of the size reported in that study. This calculation used the reported patient and control sample sizes, and the pooled SDs for patients and controls, to calculate post hoc power.

\section{RESULTS}

\section{Overview of Studies}

Of the 169 articles that were identified in the original PubMed search, 112 were excluded for any of several 
reasons. A total of 48 articles presented results from some type of spectroscopy other than proton $\left({ }^{1} \mathrm{H}\right)$ MRS (46 articles were on ${ }^{31} \mathrm{P}$ MRS and two were on ${ }^{19} \mathrm{~F}$ MRS), and another 27 articles were reviews that did not present new data. Other reasons for study exclusion were: no values for NAA were tabulated (11 studies excluded); patients had a primary diagnosis other than SZ (11 studies excluded); data presented were not from MRS (10 studies excluded); study was performed either ex vivo or in vitro (three studies excluded); study published data that appeared to be completely duplicative (one study excluded); or no control data were presented (one study excluded). This left a total of 57 articles, which were used in the secondary search.

The secondary search, in which the reference section of each primary reference was searched for relevant references, yielded an additional seven articles that had not been found by the PubMed search. Thus, the PubMed search was $89 \%$ successful (57/64) in identifying relevant references.

The final total of 64 articles that were evaluated (Table 1) includes 1256 patients and 1209 healthy controls. However, some of these tabulated studies probably include an overlapping set of patients or controls; therefore, the total subject number of 2465 may be an overestimate. The average number of subjects per study was 19.6 patients and 18.9 controls, but $72 \%$ of studies ( 46 of 64 ) had fewer than the average number of patients or controls. In fact, $53 \%$ of studies (34 of 64) had fewer than the average number of both patients and controls. Roughly $88 \%$ of all published studies (56 of 64) were performed at a magnetic field strength of $1.5 \mathrm{~T}$.

Table I Total Studies Evaluated

\begin{tabular}{lccll}
\hline Author (year) & Tesla & Cts & Pts & Patient type \\
\hline Ando et al (2002) & 1.5 & 7 & 14 & Chronic \\
Auer et al (200I) & 1.5 & 17 & 32 & Chronic \\
Bartha et al (1997) & 1.5 & 10 & 10 & FE \\
Bartha et al (1999) & 1.5 & 11 & 11 & FE \\
Bertolino et al (1996) & 1.5 & 10 & 10 & Chronic \\
Bertolino et al (1998a) & 1.5 & 14 & 14 & Childhood onset \\
& & & & (FE?) \\
Bertolino et al (1998b) & 1.5 & 12 & 12 & Chronic, drug \\
& & & & free \\
Bertolino et al (1998c) & 1.5 & 10 & 10 & Chronic \\
Bertolino et al (2000) & 1.5 & 13 & 13 & Chronic?? \\
Bertolino et al (2003) & 1.5 & 24 & 24 & FE \\
Block et al (2000) & 1.5 & 54 & 38 & Chronic \\
Brooks et al (1998) & 1.5 & 12 & 16 & Childhood onset \\
& & & & (FE) \\
Buckley et al (1994) & 1.5 & 20 & 28 & Chronic \\
Bustillo et al (200 I) & 1.5 & 21 & 38 & Chronic \\
Bustillo et al (2002a) & 1.5 & 10 & 10 & Drug-naïe FE \\
Bustillo et al (2002b) & 1.5 & 11 & 11 & Drug-naïve FE \\
Callicott et al (1998) & 1.5 & 66 & 47 & Chronic \\
Callicott et al (2000) & 1.5 & 73 & 36 & Chronic \\
Cecil et al (1999) & 1.5 & 24 & 18 & Drug-naïv FE \\
Choe et al (1994) & 1.5 & 10 & 23 & Chronic (drug \\
& & & & naïve) \\
& & & &
\end{tabular}

Table I Continued

\begin{tabular}{|c|c|c|c|c|}
\hline Author (year) & Tesla & Cts & Pts & Patient type \\
\hline Choe et al (1996) & 1.5 & 20 & 55 & Chronic \\
\hline Deicken et al (1997a) & 1.5 & 16 & 26 & Chronic \\
\hline Deicken et al (1997b) & 1.5 & 15 & 24 & Chronic \\
\hline Deicken et al (1998) & 1.5 & 18 & 30 & Chronic \\
\hline Deicken et al (1999) & 1.5 & 18 & 23 & Chronic \\
\hline Deicken et al (2000) & 1.5 & 10 & 17 & Chronic \\
\hline Deicken et al (200 la) & 1.5 & 15 & 20 & Chronic \\
\hline Delamillieure et al (2000) & 1.5 & 21 & 22 & Chronic?? \\
\hline Delamillieure et al (2002) & 1.5 & 14 & 17 & Chronic \\
\hline Eluri et al (1998) & 1.5 & 8 & 12 & Chronic \\
\hline Ende et al (2000) & 1.5 & 16 & 19 & Chronic \\
\hline Ende et al (200I) & 1.5 & 15 & 15 & Chronic \\
\hline Ende et al (2003) & 1.5 & 15 & 13 & Chronic \\
\hline Fannon et al (2003) & 1.5 & 18 & 33 & FE \\
\hline Fujimoto et al (1996) & 2 & 12 & 14 & Chronic \\
\hline Fukuzako et al (1995) & 2 & 15 & 15 & Chronic \\
\hline Fukuzako et al (1999) & 2 & 40 & 40 & Chronic \\
\hline Fukuzako (2000) & 2 & 51 & 64 & Chronic \\
\hline Gimenez et al (2003) & 1.5 & 11 & 11 & $\mathrm{FE}$ \\
\hline Hagino et al (2002) & 1.5 & 13 & 13 & Chronic \\
\hline Heimberg et al (1998) & 1.5 & 39 & 24 & Chronic \\
\hline Kegeles et al (2000) & 1.5 & 10 & 10 & Chronic \\
\hline Lim et al (1998) & 1.5 & 9 & 10 & Chronic \\
\hline Maier et al (1995) & 1.5 & 32 & 25 & Chronic \\
\hline Maier and Ron (1996) & 1.5 & 38 & 26 & Chronic \\
\hline Moore et al (2002) & 1.5 & 20 & 20 & Chronic \\
\hline Nasrallah et al (1994) & 1.5 & 11 & II & Chronic \\
\hline Ohara et al (2000) & 1.5 & 10 & 10 & Chronic \\
\hline Omori et al (2000) & 1.5 & 16 & 20 & Chronic \\
\hline O'Neill et al (2004) & 1.5 & 20 & 11 & $\begin{array}{l}\text { Childhood } \\
\text { onset (FE) }\end{array}$ \\
\hline Renshaw et al (1995) & 1.5 & 15 & 7 & FE \\
\hline Sharma et al (1992) & 1.5 & 9 & 4 & Chronic \\
\hline Shioiri et al (1996) & 1.5 & 21 & 21 & Chronic \\
\hline Sigmundsson et al (2003) & 1.5 & 26 & 25 & Chronic \\
\hline Spaniel et al (2003) & 1.5 & I & । & Chronic \\
\hline Stanley et al (1996) & 1.5 & 24 & || & Drug-naïve FE \\
\hline Steel et al (200I) & 2 & 10 & 10 & Chronic \\
\hline Theberge et al (2002) & 4 & 21 & 21 & Drug-naïve FE \\
\hline Theberge et al (2003) & 4 & 21 & 21 & Chronic \\
\hline Thomas et al (1998) & 1.5 & 12 & 12 & $\begin{array}{l}\text { FE children and } \\
\text { adolesc. }\end{array}$ \\
\hline Tibbo et al (2000) & 3 & 12 & 12 & Chronic \\
\hline Weber-Fahr et al (2002) & 1.5 & 15 & 15 & Chronic \\
\hline Yamasue et al (2002) & 1.5 & 13 & 15 & Chronic \\
\hline \multirow[t]{3}{*}{ Yurgelun-Todd et al (1996) } & 1.5 & 14 & 16 & Chronic \\
\hline & $\begin{array}{l}\text { Total \# } \\
\text { subjects }\end{array}$ & 1209 & 1256 & \\
\hline & $\begin{array}{l}\text { Average } \\
\text { subjects/ } \\
\text { study }\end{array}$ & 18.9 & 19.6 & \\
\hline
\end{tabular}

$\mathrm{FE}=$ first episode; adolesc $=$ adolescent; $\mathrm{Cts}=$ controls; $\mathrm{Pts}=$ patients 
Most studies (77\% or 49 of 64 ) focused on patients with chronic SZ, as there have been only 14 studies of FE patients, of which four studies were of patients with juvenile-onset SZ. In total, only 167 adolescent or adult FE patients have been studied; therefore, relatively little is known about whether the brain of a typical newly diagnosed patient is different from normal.

\section{Brain Metabolite Levels}

To determine whether the approach of normalizing patient values to control values is a valid way to compare between studies, we tabulated patient hippocampal NAA levels measured in arbitrary units of NAA concentration $v s$ as a ratio of NAA/Cr (Table 2). This comparison was carried out in hippocampus because this tissue is of relevance in SZ; therefore, there have been a fairly large number of studies that focus on hippocampus. The apparent equivalence of patient NAA levels after normalization to control levels, whether patient NAA levels were originally expressed as [NAA] or NAA/Cr, suggests that normalization to control values is a valid way to compare across studies. As this approach references patient values to concurrently collected control values, this should even make it possible to compare between different field strengths. Results suggest that hippocampal NAA is reduced about $10 \%$ in patients compared to controls. These results appear to be robust, as most studies ( $80 \%$ or 12 of 15 ) report a significant reduction in NAA among patients (Table 2).
The question of whether normalizing patient values to control values is a valid approach to compare between studies is crucial to our purpose; therefore, we also did a meta-analysis of these data (Figure 1). In evaluating studies which presented NAA as a raw value, there was a significant reduction in NAA in patient hippocampus compared to control hippocampus $(p<0.0001)$, although there was significant heterogeneity between studies $(p<0.0001)$. The least-squares (LS) mean NAA in patients was $15.37 \mathrm{U}(95 \%$ confidence interval (CI): 14.64-16.10 U), whereas the LS mean NAA in controls was 18.18 U (95\% CI: 17.45-18.90). Thus, the ratio of patient to control NAA by LS mean raw values was $84.5 \%$.

In evaluating studies that presented $\mathrm{NAA}$ as a ratio of $\mathrm{NAA} / \mathrm{Cr}$, there was also a significant reduction in NAA/Cr in patient hippocampus compared to control hippocampus $(p<0.0001)$, although there was again significant heterogeneity between studies $(p<0.0001)$. The LS mean NAA/Cr ratio in patients was $1.47 \mathrm{U}$ (95\% CI: $1.39-1.54 \mathrm{U}$ ), whereas the LS mean NAA/Cr ratio in controls was 1.70 (95\% CI: 1.63-1.77). The ratio of patient to control NAA by LS ratios was thus $86.5 \%$, which is similar to the ratio by raw values (Figure 1).

There is consistent evidence that NAA is reduced in a broad range of tissues in the SZ brain (Table 3). The extent of reduction of NAA in GM is generally comparable to the extent of reduction of NAA in WM. However, this comparison of GM to WM is confounded by what appears to be regional variation in the extent of brain NAA

Table 2 Metabolite Measurements made in Hippocampus of Schizophrenic Patients at I.5T

\begin{tabular}{|c|c|c|c|c|c|c|c|c|c|c|}
\hline \multicolumn{5}{|c|}{ NAA in patients (relative to controls) } & \multicolumn{6}{|c|}{ Reported values for [NAA] or NAA/Cr } \\
\hline & [NAA] & NAA/Cr & Author (year) & $\begin{array}{c}\text { Reported } \\
p \text {-value }\end{array}$ & $\begin{array}{l}\text { Patient } \\
\text { (mean) }\end{array}$ & $\begin{array}{l}\text { Patient } \\
\text { (SD) }\end{array}$ & $\begin{array}{l}\mathrm{Pt} \\
(n)\end{array}$ & $\begin{array}{l}\text { Control } \\
\text { (mean) }\end{array}$ & $\begin{array}{l}\text { Control } \\
\text { (SD) }\end{array}$ & $\begin{array}{l}C t \\
(n)\end{array}$ \\
\hline & 85 & - & Deicken et al (1998) & 0.002 & 33.80 & 6.20 & 30 & 39.60 & 6.80 & 18 \\
\hline & 85 & - & Deicken et al (1999) & 0.005 & 33.20 & 6.00 & 23 & 39.20 & 6.60 & 18 \\
\hline & 92 & - & Ende et al (2003) & 0.004 & 11.80 & 1.00 & 13 & 12.90 & 0.80 & 15 \\
\hline & 80 & - & Maier and Ron (1996) & - & 6.40 & 2.04 & 26 & 8.00 & 2.71 & 38 \\
\hline & 94 & - & Weber-Fahr et al (2002) & 0.013 & 1.63 & 0.12 & 15 & 1.74 & 0.11 & 15 \\
\hline & - & 85 & Bertolino et al (1996) & 0.03 & 1.71 & 0.23 & 10 & 2.02 & 0.26 & 10 \\
\hline & - & 90 & Bertolino et al (1998a) & 0.05 & 1.70 & $N R$ & 14 & 1.90 & $N R$ & 14 \\
\hline & - & 84 & Callicott et al (1998) & 0.00001 & 1.60 & 0.30 & 47 & 1.90 & 0.50 & 66 \\
\hline & - & 111 & Delamillieure et al (2002) & - & 1.26 & 0.29 & 11 & 1.14 & 0.16 & 14 \\
\hline & - & 84 & Fannon et al (2003) & 0.0002 & 0.81 & 0.13 & 11 & 0.96 & 0.10 & 14 \\
\hline & - & 89 & Kegeles et al (2000) & - & 1.52 & 0.28 & 10 & 1.70 & 1.02 & 10 \\
\hline Mean & 85.8 & 88.8 & & & & & & & & \\
\hline SD & 6.1 & 8.7 & & & & & & & & \\
\hline
\end{tabular}

Both [NAA] and NAA/Cr are reported for patients as a percentage of the values reported for controls in the same study, to normalize across studies. Values to the right of the vertical bar were used to perform a meta-analysis contrasting the two methods of reporting NAA levels. If left and right hippocampus were separately reported, only the left hippocampus values are analyzed here. Papers by Bertolino (1998a, c) were excluded from the meta-analysis because sample standard deviation (SD) was not reported (NR) in the original paper. 


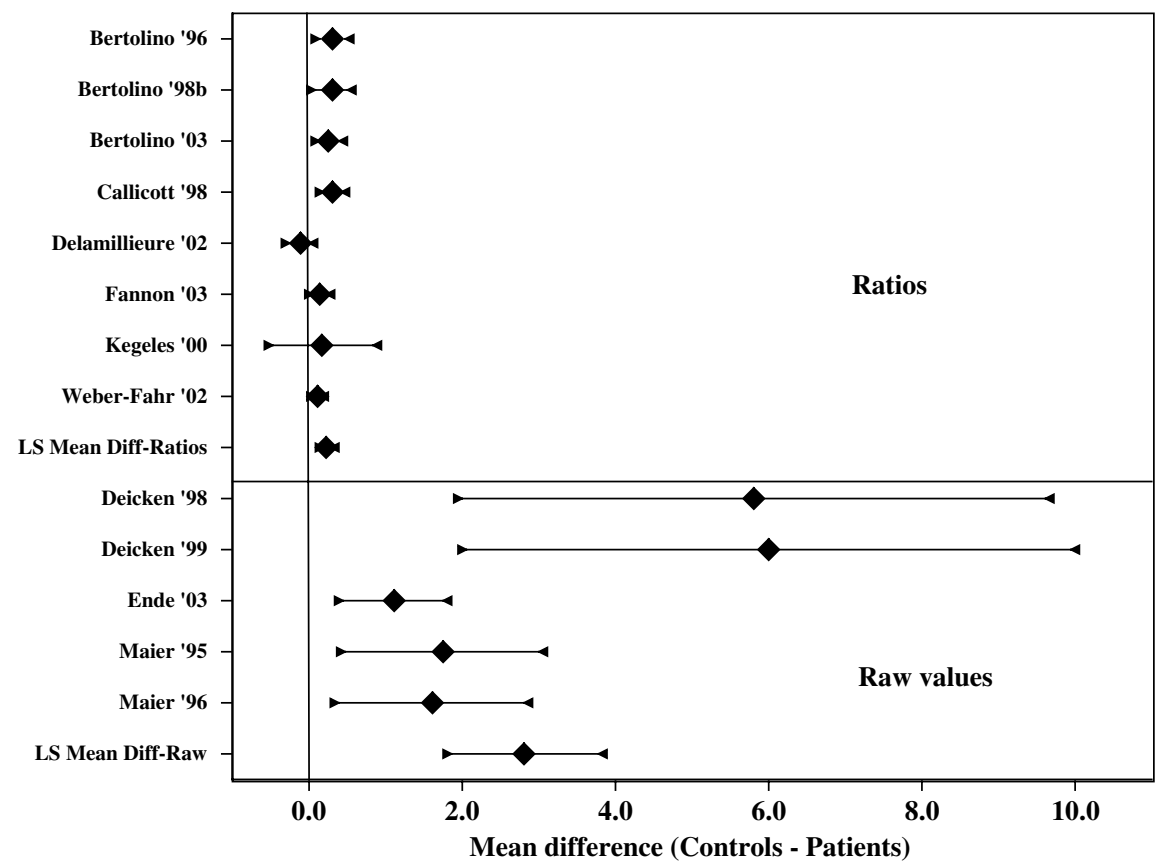

Figure I Visual summary of a meta-analysis of NAA levels in the hippocampus of patients with schizophrenia (SZ) compared to healthy controls (data from Table 2). NAA levels expressed in ratios are shown separately from NAA levels expressed in raw values. There is no apparent trend difference, depending upon how NAA levels were expressed in the original paper, suggesting that calculating patient NAA values as a proportion of control NAA values is a valid way to compare between studies.

reduction in patients. For example, NAA levels do not appear to be reduced in SZ patients in basal ganglia, caudate, occipital cortex, posterior cingulate, putamen, centrum semiovale, or parietal WM. However, levels of NAA do appear to be substantially reduced $(>5 \%)$ in the cerebellum, frontal cortex, hippocampus, parietal cortex, temporal cortex, frontal WM, and temporal WM. At least 10 published studies provide evidence that there is a substantial $(>5 \%)$ and often significant reduction in levels of NAA in the hippocampus, and in both the cortical GM and WM of the frontal lobe. However, because NAA levels in all GM tissues and all WM tissues were combined (Table 3), without considering regional variation in NAA (Auer et al, 2001), a direct comparison of GM to WM may be confounded. Nevertheless, we note that there is no compelling evidence to suggest that NAA is significantly elevated in any brain tissue in patients with SZ (Table 3).

To explore further whether NAA levels in patients are reduced to an equivalent degree in GM and in WM, NAA levels in the frontal lobe are tabulated separately for the two tissue types (Table 4). This comparison suggests that NAA is reduced to a comparable degree in frontal lobe GM and frontal lobe WM, despite some findings to the contrary (Bertolino et al, 1996, 1998a, b). Furthermore, although the data are quite sparse, there is no convincing evidence that levels of choline (Cho) or Cr differ in GM or WM of the frontal lobe. We note that this analysis does not mean that levels of NAA (or $\mathrm{Cr}$ or Cho) are equivalent in healthy gray and WM, but rather that levels of NAA are reduced to an equivalent degree in both gray and WM of the SZ brain.

We undertook a meta-analysis of the data in Table 4, to test further whether frontal lobe GM and frontal lobe WM show a significant reduction in NAA (Figure 2). In frontal lobe GM, there was a significant reduction in patient NAA compared to control frontal lobe GM $(p<0.0008)$, although there was significant heterogeneity between studies $(p<0.0001)$. The LS mean NAA in patients was $4.12 \mathrm{U}$ (95\% CI: 4.03-4.21 U), whereas the LS mean NAA in controls was $4.31 \mathrm{U}$ (95\% CI: 4.23-4.39 U). Thus, the ratio of patient to control NAA in frontal lobe GM was $95.6 \%$ by LS mean raw values.

In frontal lobe WM, there was also a significant reduction in patient NAA, as compared to control frontal lobe WM $(p<0.0001)$, with significant heterogeneity between studies $(p<0.0001)$. The LS mean NAA in patients was $5.98 \mathrm{U}(95 \%$ CI: 5.79 to $6.16 \mathrm{U}$ ), whereas the LS mean NAA in controls was $6.48 \mathrm{U}$ (95\% CI: 6.30-6.66 U). Thus, the ratio of patient to control NAA in frontal lobe WM was $92.3 \%$ by LS mean raw values. These results may mean that there was greater reduction of NAA in WM than GM. However, the degree of heterogeneity between studies precludes a direct metaanalytic comparison of GM to WM in frontal lobe.

To determine whether FE patients are comparable to patients with chronic SZ, NAA levels in the prefrontal cortex (excluding anterior cingulate) were tabulated separately for each patient group (Table 5). Given the small sample size of FE patients, this comparison does not provide convincing evidence of a difference in NAA levels between patients as a function of disease duration. The trend towards lower NAA in FE patients is not convincing, yet it seems clear that NAA levels are probably not lower in chronic patients, as was expected. Nevertheless, there is a robust reduction of NAA in prefrontal cortex. When this type of analysis was also undertaken for anterior cingulate and temporal lobe (data not shown), there was likewise no convincing evidence for a difference between FE and chronic patients. 
Table 3 Summary of NAA Levels in all Studies, Separated by Tissue Type and Brain Region

\begin{tabular}{|c|c|c|}
\hline \multirow[b]{2}{*}{ Brain region } & \multicolumn{2}{|c|}{ Patient NAA (as $\%$ of control) } \\
\hline & $\begin{array}{l}\text { Total } n \text { studies } \\
\quad \text { evaluated }\end{array}$ & $\begin{array}{c}\text { Mean across } \\
n \text { studies }\end{array}$ \\
\hline \multicolumn{3}{|l|}{ Gray matter (GM) } \\
\hline Anterior cingulate GM & 12 & 95.9 \\
\hline Basal ganglia & 6 & 98.5 \\
\hline Caudate & 3 & 100.3 \\
\hline Cerebellum & 3 & 92.3 \\
\hline Frontal cortex & 25 & 94.2 \\
\hline Hippocampus & 17 & 88.9 \\
\hline Lenticular nucleus & 2 & 104.5 \\
\hline Occipital cortex & 8 & 102.8 \\
\hline Parietal cortex & 1 & 94.0 \\
\hline Post cingulate & 5 & 100.0 \\
\hline Putamen & 7 & 100.6 \\
\hline Striatum & । & 112.6 \\
\hline Temporal cortex & 5 & 94.0 \\
\hline Thalamus & 19 & 96.5 \\
\hline Total \# comparisons & 114 & \\
\hline GM average across comparisons & & 95.5 \\
\hline \multicolumn{3}{|l|}{ White matter (WM) } \\
\hline Centrum semiovale & 5 & 100.2 \\
\hline Frontal lobe WM & 18 & 94.8 \\
\hline Occipital WM & । & 96.0 \\
\hline Parietal WM & 2 & 99.0 \\
\hline Temporal WM & 8 & 87.3 \\
\hline Total \# comparisons & 34 & \\
\hline $\begin{array}{l}\text { WM average across } \\
\text { comparisons }\end{array}$ & & 94.2 \\
\hline
\end{tabular}

The total number of comparisons is larger than the number of studies because some studies reported more than one comparison. All studies for a given tissue are combined without weighting for sample size. For example, there are 12 studies that report NAA levels in GM of the anterior cingulate; each study was treated as a 'vote' and the mean across all 12 votes was calculated, irrespective of sample size in each study.

We summarize the CV of measured NAA levels in all studies of the frontal lobe (Table 6), to address the question of study reliability. We elected to do this analysis in frontal lobe because ROIs in the frontal lobe tend to be rather large (by comparison to the hippocampus, for example); therefore, measurements made in the frontal lobe should be more reliable than those made in many other parts of the brain. This tabulation shows that the average CV for both patients and controls is about $14 \%$ across all studies. Studies with a CV smaller than $14 \%$ are more likely to detect small differences between patients and controls, and so would be expected to have a greater likelihood of having statistically significant findings. Conversely, studies with a CV larger than normal are less likely to report significant findings.
Therefore, a study with a large CV that also has a low associated $p$-value is more likely to be reporting spurious findings.

We show the results of post hoc power calculations, to address whether MRS studies were adequately powered to detect the NAA differences that they report (Table 6). Power calculations in general are imprecise estimates, based on estimates of variation and effect size that are of uncertain accuracy. Post hoc power calculations estimate the power of a completed study to reject the null hypothesis, given the sample size used in the study. These calculations assume that the population effect size is equal to the sample effect size, that the population variance is equal to the sample variance, and that all statistical tests were two sided. The average statistical power of all measurements across the 16 tabulated studies was $37 \%$. If adequate power is assumed to be at least $80 \%$, then only four measurements in three studies had adequate power. Overall, 12 of 16 studies reported at least one comparison with less than $50 \%$ power to detect a difference of the magnitude reported (Table 6). If one were to assume an a priori hypothesis that NAA is reduced in patients, relative to healthy controls, one could argue that a one-sided statistical test is appropriate. With such an assumption, the power of the statistical tests would increase, because of the implied directionality of change. However, while a one-sided test may be appropriate now, it was probably not appropriate when most of these studies were carried out, since there was no a priori reason to assume that NAA was reduced in patients.

Required sample sizes for adequate power can be calculated if we assume that NAA levels in controls are $13.4 \pm 2.0 \mathrm{U}$ SD, which is approximately the mean and SD of all studies tabulated in Table 6 (data not shown). We further assume that patient NAA levels are $10 \%$ lower than control NAA levels (Tables 2, 3, and 5), and that the SD in patients and controls is equal. If $80 \%$ power to detect a $10 \%$ difference in NAA is the goal, then a minimum sample size of 39 patients and 39 controls is needed. If either the desired statistical power is increased or the actual difference in NAA between patients and controls is decreased, then required sample sizes would increase accordingly. For example, if the goal was to have $80 \%$ power to detect a $5 \%$ difference in NAA, will all other assumptions remain the same, then a minimum sample size of 130 patients and 130 controls would be required.

This analysis confirms that most studies performed to date are underpowered. For example, only three of 64 studies (Table 1) were large enough to have $80 \%$ power to detect a 10\% NAA difference between patients and controls, and only one study was large enough to have $90 \%$ power to detect such a $10 \%$ NAA difference. No studies were adequately powered to detect a $5 \%$ difference in mean NAA between patients and controls.

\section{DISCUSSION}

Evidence is accumulating to suggest that there are MRS differences between controls and SZ patients, although these differences may be rather subtle (Table 3). At least 10 published studies provide evidence that there is a substantial $(>5 \%)$ and often significant reduction in NAA 
Table 4 Metabolite Levels in Frontal Lobe, as a Function of Tissue Type (GM and WM)

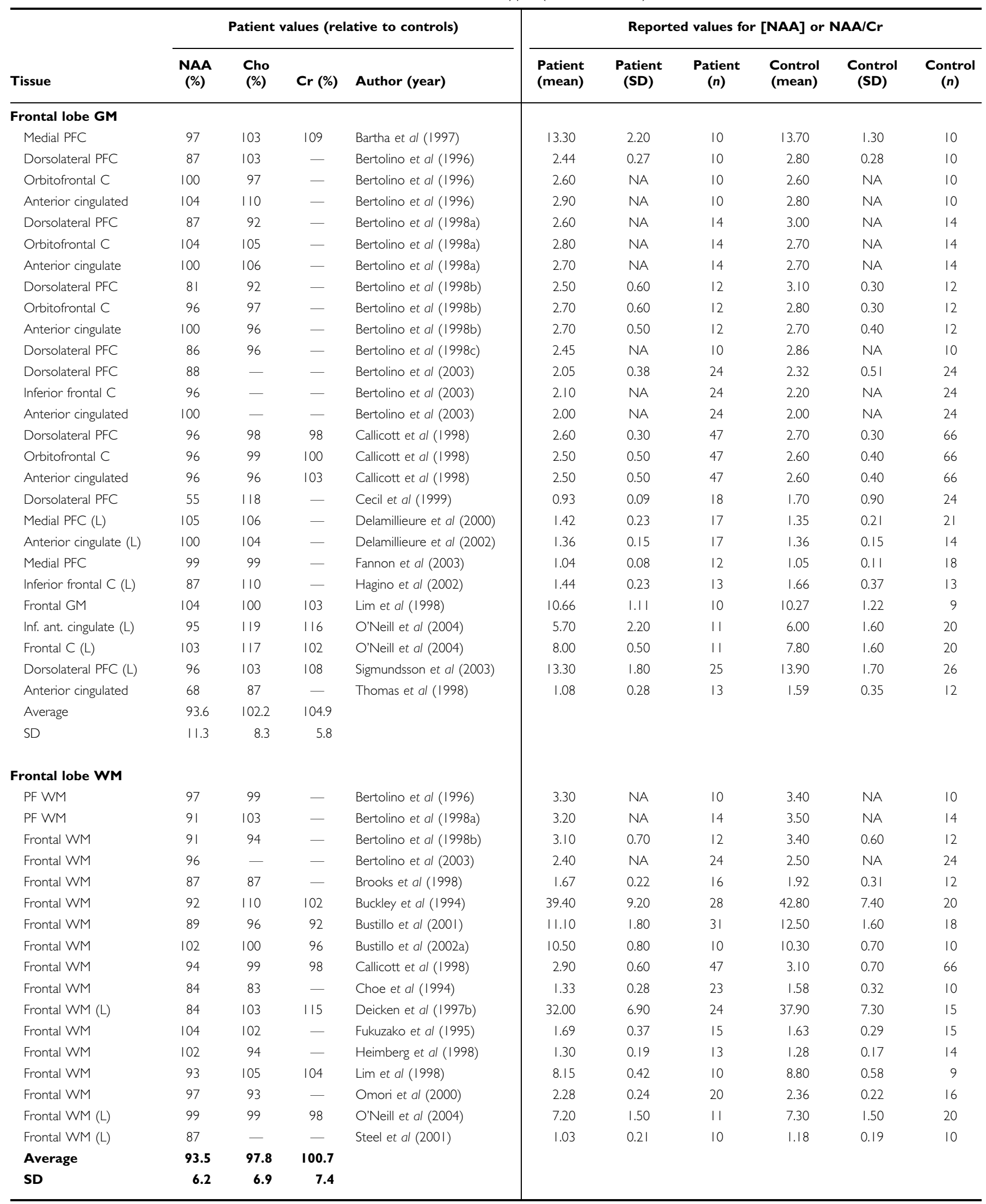

$\mathrm{PFC}=$ prefrontal cortex; $\mathrm{PF}=$ prefrontal; $\mathrm{WM}=$ white matter; $\mathrm{NA}=$ not available; $\mathrm{C}=$ cortex .

Data to the right of the vertical line was used in the meta-analysis.

Cells containing a dash indicate that the data were not presented in the original paper 


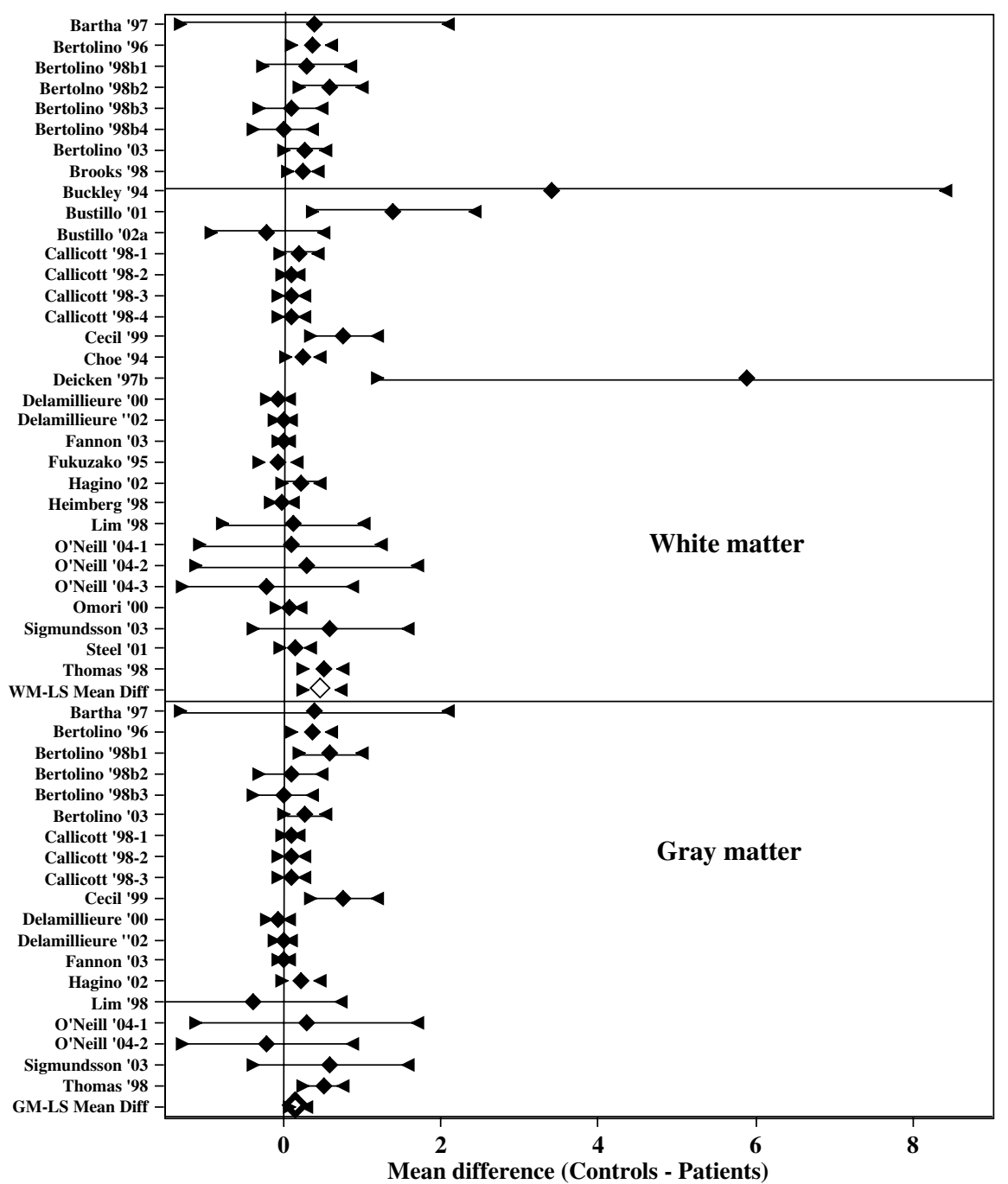

Figure 2 Visual summary of a meta-analysis of NAA levels in WM of the frontal lobe and in GM of the frontal lobe of patients with schizophrenia (SZ) compared to healthy controls (data from Table 4). There is no apparent difference between patient WM and patient GM, in the extent of reduction of NAA levels.

levels in hippocampus and in cortical GM and WM of the frontal lobe. No other tissues show as well corroborated or convincing a reduction of NAA in SZ patients (Table 3). There is little evidence to support a hypothesis that GM and WM differ in relative NAA levels (Table 4), or that chronic patients have a lower level of NAA than FE patients (Table 5).

Most (eight of 15) published studies of the hippocampus report a highly significant $(p<0.01)$ reduction of NAA in patients, with an average difference of $10 \%$ (Table 2). Our meta-analysis confirms that the reduction of NAA in patients is significant, whether NAA is characterized as a raw value $(p<0.0001)$ or as the ratio of $\mathrm{NAA} / \mathrm{Cr}$ $(p<0.0001)$. This is somewhat surprising, given that power calculations suggest that only one of these studies had $80 \%$ power to detect a reduction of NAA of $10 \%$ in patients. This suggests that there may be a publication bias in the literature, such that studies which report a significant difference between patients and controls are more likely to be published than are studies that report no such differences. More work will be needed to determine whether the differences in hippocampal NAA that have been reported between patients and controls are real and meaningful.

A potential weakness of our analytic approach is that simply measuring NAA levels provides little or no specificity as to the disease process inherent to SZ, since brain NAA is reduced in a broad range of illnesses. Extensive evidence confirms that NAA levels are lower than normal in patients with tumor or stroke (Zimmerman and Wang 1997; Taylor et al, 1998), but recent evidence shows that NAA is also reduced in traumatic brain injury (Ariza et al, 2004), multiple sclerosis (Gadea et al, 2004; Tartaglia et al, 2004), epilepsy (Bernasconi et al, 2003; Vermathen et al, 2003), vascular dementia (Schuff et al, 2003), Alzheimer disease (Dixon et al, 2002; Valenzuela and Sachdev, 2001), Huntington disease (Sanchez-Pernaute et al, 1999), spinocerebellar ataxia (Guerrini et al, 2004), perinatal asphyxia (Pavlakis et al, 1999), transposition of the great arteries (Miller et al, 2004), mood disorder (Cecil et al, 2003), gliomatosis cerebri (Galanaud et al, 2003), focal cortical dysplasia (Vuori et al, 2004), and radiation necrosis 
Table 5 Findings in Prefrontal Cortex (Excluding Anterior Cingulate) of FE and Chronic SZ Patients

\begin{tabular}{|c|c|c|c|c|c|c|c|c|}
\hline \multirow[b]{2}{*}{ Author (year) } & \multirow[b]{2}{*}{ NAA (\%) } & \multicolumn{7}{|c|}{ Reported values for [NAA] or NAA/Cr } \\
\hline & & $\begin{array}{c}\text { Original } \\
\text { ( } p \text {-value) }\end{array}$ & $\begin{array}{l}\text { Patient } \\
\text { (mean) }\end{array}$ & $\begin{array}{c}\text { Patient } \\
\text { (SD) }\end{array}$ & $\begin{array}{l}\text { Patient } \\
\text { (n) }\end{array}$ & $\begin{array}{l}\text { Control } \\
\text { (mean) }\end{array}$ & $\begin{array}{c}\text { Control } \\
\text { (SD) }\end{array}$ & $\begin{array}{c}\text { Control } \\
\text { (n) }\end{array}$ \\
\hline \multicolumn{9}{|l|}{ FE patients } \\
\hline Bertolino et al (1998a) & 86 & 0.009 & 2.54 & NR & 14 & 2.97 & NR & 14 \\
\hline Bertolino et al (2003) & 99 & - & 2.14 & NR & 24 & 2.17 & NR & 24 \\
\hline Cecil et al (1999) & 57 & 0.0006 & 0.96 & 0.38 & 18 & 1.70 & 0.34 & 24 \\
\hline Total & & & & & 72 & & & 74 \\
\hline Average & 82.3 & & & & & & & \\
\hline SD & 17.8 & & & & & & & \\
\hline Bertolino et al (1998b) & 82 & 0.004 & 2.53 & 0.61 & 12 & 3.09 & 0.26 & 12 \\
\hline Bertolino et al (1998c) & 86 & 0.001 & 2.45 & $N R$ & 10 & 2.86 & $N R$ & 10 \\
\hline Block et al (2000) & 94 & - & 2.75 & 0.28 & 25 & 2.93 & 0.35 & 19 \\
\hline Buckley et al (1994) & 92 & - & 39.40 & 9.20 & 20 & 42.80 & 7.40 & 15 \\
\hline Callicott et al (1998) & 97 & - & 2.65 & 0.36 & 47 & 2.74 & 0.41 & 66 \\
\hline Hagino et al (2002) & 87 & - & 1.44 & 0.23 & 13 & 1.66 & 0.37 & 13 \\
\hline Sigmundsson et al (2003) & 96 & - & 13.30 & 1.80 & 25 & 13.90 & 1.70 & 26 \\
\hline Total & & & & & 162 & & & 171 \\
\hline Average & 90.1 & & & & & & & \\
\hline
\end{tabular}

$\mathrm{SD}=$ standard deviation; $n=$ sample size; $\mathrm{NR}=$ not reported.

(Dowling et al, 2001). As NAA reduction is characteristic of such an extraordinarily broad range of diseases, the abundance of NAA in the brain offers little or no insight into the disease process inherent to SZ.

A second potential weakness of our analytic approach is that we have treated NAA as if it was the only information available by MRS, and this is not true (Omori et al, 1997). In fact, measurement of NAA alone is clearly not sufficient to make a clinical diagnosis, since the spectra acquired from patients with a broad range of brain diseases are often quite similar in having low NAA. There are other abundant brain metabolites, such as Cho and $\mathrm{Cr}$, which are clearly visible in patient spectra, and there are additional metabolites, including lipid, lactate, glutamate, GABA, and inositol, which are in still lower abundance and can be very hard to discern in patient spectra. To understand disease processes in the brain, investigators must analyze these other resonances, in addition to NAA (Richards, 1991). Nevertheless, the analysis presented here (Table 6) suggests that even NAA is seldom measured with enough precision to provide a clear picture of disease processes. Resonances other than NAA, because they are less easily resolved by MRS, are measured with substantially less precision than is possible for NAA (Mullins et al, 2003). The only way to overcome the problems inherent to an insensitive metho- dology such as MRS is to improve the precision of the measurement or to accrue a large number of subjects. We note that it is especially important to validate the precision of MRS methodology in any study that involves data collection at multiple sites (Komoroski et al, 2004).

A third potential weakness of our analytic approach is that we assume that all studies are of equal validity, and this also is not true. Studies with large sample sizes have greater statistical power than small studies, even if the $p$-values are similar (Table 6). Yet, some studies with a reasonable sample size could still be weakened by inadequate methodology. We have not attempted to discern which studies are more likely to be methodologically robust, for several reasons: firstly, it is essentially impossible to determine methodological rigor from the brief description of methods that is typically published in a nonspecialty journal; secondly, in the absence of an objective way to determine which studies are rigorous, it would be wrong to rely upon hearsay evidence as to which studies are flawed; and finally, older studies are more likely to be methodologically flawed than are newer studies, but they are also more likely to be seminal or published by senior researchers. We believe that criticizing a study for being formative would be foolish. As an example of the increased methodological rigor that is characteristic of more recent 
Table 6 CV of NAA (Units of [NAA] or NAA/Cr) and Study Power in Frontal Lobe at I.5T

CV of NAA and power calculation for each study

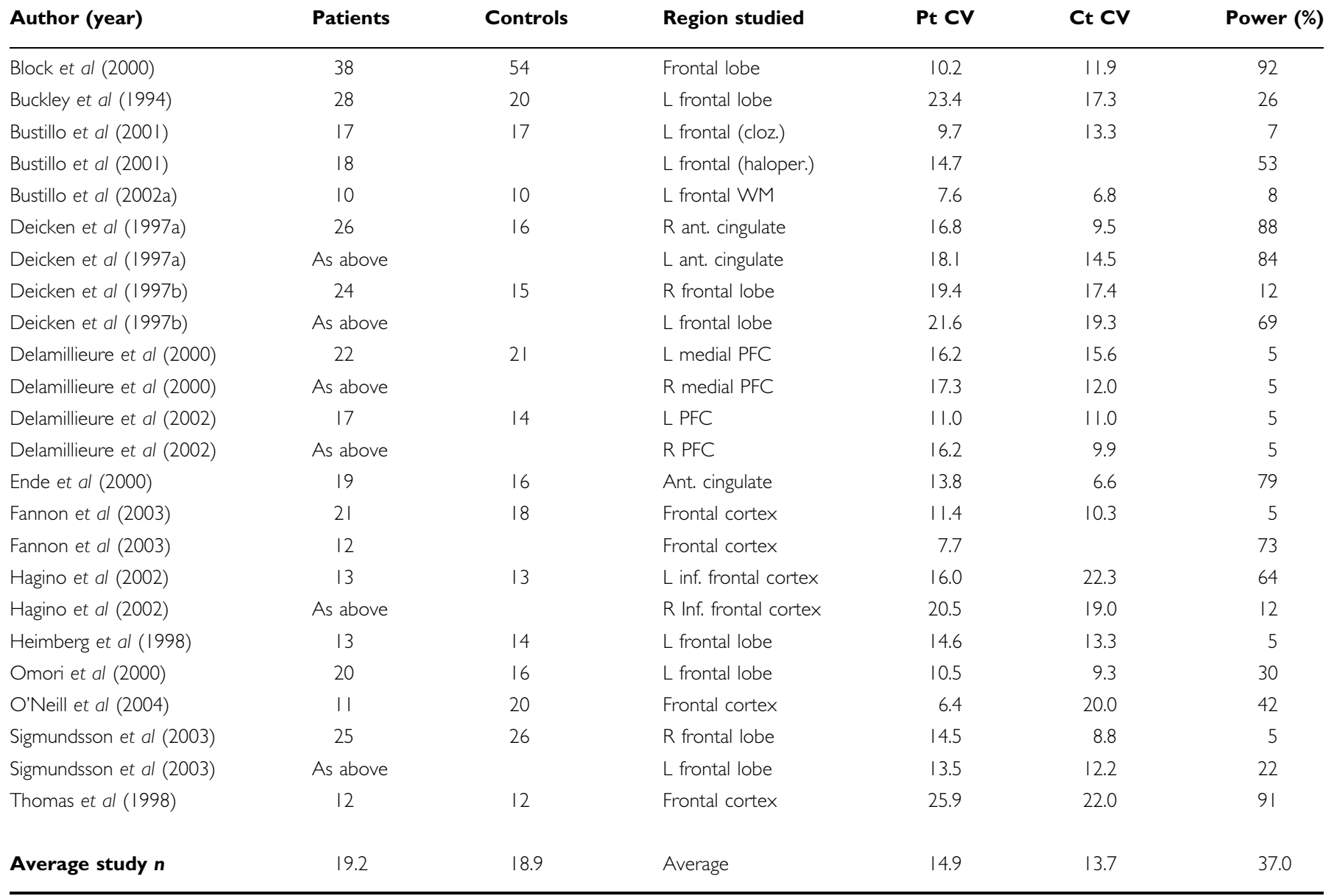

Pt = patient; $c t=$ control; $L=$ left hemisphere; $R=$ right hemisphere; $W M=$ white matter; Inf. $=$ inferior; $n=$ sample size; PFC = prefrontal cortex.

This tables includes only papers that tabulated means and standard deviations (SD) of data. Power of each study to detect the difference reported was calculated with NQuery using patient and control means and the pooled SD calculated from the patient and control standard deviations.

studies, we note that many early studies did not properly match patients to controls by demographics; it would be problematic to match patients to controls by NAA levels, if they were not properly matched by age.

Nevertheless, the analysis we present can offer some unique insights. If NAA reduction is localized, this can potentially provide a clue as to the locus of brain injury. For example, NAA appears to be reduced in the thalamus of patients with idiopathic generalized epilepsy (Bernasconi et al, 2003), and a significant negative correlation was found between thalamic NAA/Cr and the duration of epilepsy, whereas NAA was not reduced in any other brain region examined in such patients. This finding argues that progressive thalamic neuronal dysfunction may be involved in idiopathic generalized epilepsy (Bernasconi et al, 2003). If we extend this argument, by asking if there are specific loci of brain abnormality in patients with SZ, the answer is less clearcut (Table 3 ). The only tissues for which there are well-replicated and robust findings of NAA reduction are the frontal lobe, including both cortical GM and WM, and the hippocampus. Evidence of NAA reduction is weaker in tissues of the basal ganglia, in brain lobes other than the frontal lobe, or in the midbrain (Table 3). Therefore, the evidence of NAA deficit is fairly strong in the same tissues for which evidence of a volumetric deficit in patients is strong (Shenton et al, 2001). Some reports suggest that there is no relationship between NAA reduction and volumetric loss (Deicken et al, 1999), but it seems reasonable nonetheless, to propose that frontal lobe and hippocampus are key loci of brain injury or abnormality in SZ.

There is recent evidence that treatment with antipsychotic medication can have an effect on NAA levels in SZ patients (Fannon et al, 2003; Bertolino et al, 2001). Patients treated with atypical antipsychotics had higher levels of NAA in hippocampus than did patients treated with haloperidol (Fannon et al, 2003). A longitudinal within-subjects design was used to evaluate 23 chronic SZ patients, first when they were drug free (either drug naïve or off medication for at least 2 weeks), then again after they had been stably medicated for at least 4 weeks. Spectra acquired by spectroscopic imaging were analyzed for relative changes in NAA, with 11 brain regions assessed. Patient NAA levels increased significantly in as little as 4 weeks in the dorsolateral prefrontal cortex (DLPFC), but in none of the 
other 10 brain regions. As the experimental design of this study used each patient as their own control, relatively small changes in NAA were potentially significant (Bertolino et al, 2001). Another study, which did not use a within-subjects design, also reported that NAA levels were higher among patients on atypical antipsychotics (clozapine or risperidone) than among patients on typical antipsychotics (Braus et al, 2001, 2002). Furthermore, the longer patients had been treated with atypical antipsychotics, the higher were levels of NAA in the anterior cingulate, suggesting that atypical antipsychotics may reverse the NAA decrease seen in chronic SZ (Braus et al, 2001, 2002). These results, while preliminary, suggest that NAA levels can change acutely, in response to medication, over a fairly short period of time. This would tend to argue against the current conception of NAA as a marker of neuronal viability (Meyerhoff et al, 1993).

The NAA peak has been hypothesized to be a marker of the number of viable neurons in brain tissue (Meyerhoff et al, 1993), but evidence is beginning to accumulate against this simple hypothesis. For example, a case report of a child with mild mental retardation showed no NAA resonance at all in the brain (Martin et al, 2001). The NAA peak can decrease transiently after acute brain injury (de Stefano et al, 1995), and NAA can show stable increases after therapy for moya-moya (Shimizu et al, 1997), amyotrophic lateral sclerosis (Kalra et al, 1998), or Wernicke encephalopathy (Mascalchi et al, 2002). The finding that NAA deficits can be reversed over a relatively short period of time argues strongly that NAA is not a reliable marker of neuronal loss (Barker, 2001). Furthermore, NAA can be chronically elevated in certain disease states that are not known to be associated with neuronal proliferation, including Asperger syndrome (Murphy et al, 2002), sickle cell disease (Steen and Ogg, 2005), Pelizaeus-Merzbacher disease (Takanashi et al, 2002), Canavan disease (Matalon et al, 1995), and familial bipolar I disorder (Deicken et al, 2001b). These results are not consistent with the proposed role of NAA as a neuronal marker (Bertolino and Weinberger, 1999; de Stefano et al, 1995; Barker, 2001; Steen and Ogg, 2005); thus, NAA reduction in SZ patients cannot be interpreted as suggesting neuronal depletion in disease.

\section{ACKNOWLEDGEMENTS}

Dr Steen is supported by the National Alliance for Research on Schizophrenia and Depression (NARSAD) as a Hofmann Trust Investigator. Our research was also supported by MH61603 (Dr JA Lieberman), the University of North Carolina at Chapel Hill Schizophrenia Research Center, an NIMH Silvio Conte Center for the Neuroscience of Mental Disorders (MH64065), and the Foundation of Hope.

\section{REFERENCES}

Ando K, Takei N, Matsumoto H, Iyo M, Isoda H, Mori N (2002). Neural damage in the lenticular nucleus linked with tardive dyskinesia in schizophrenia: a preliminary study using proton magnetic resonance spectroscopy. Schizophr Res 57: 273-279.

Ariza M, Junque C, Mataro M, Poca MA, Bargallo N, Olondo M et al (2004). Neuropsychological correlates of basal ganglia and medial temporal lobe NAA/Cho reductions in traumatic brain injury. Arch Neurol 61: 541-544.

Auer DP, Wilke M, Grabner A, Heidenreich JO, Bronisch T, Wetter TC (2001). Reduced NAA in the thalamus and altered membrane and glial metabolism in schizophrenic patients detected by ${ }^{1}$ H-MRS and tissue segmentation. Schizophr Res 52: 87-99.

Barker PB (2001). N-acetyl aspartate - a neuronal maker? Ann Neurol 49: 423-424.

Bartha R, Al-Semaan YM, Williamson PC, Drost DJ, Malla AK, Carr TJ et al (1999). A short echo proton magnetic resonance spectroscopy study of the left mesial-temporal lobe in first-onset schizophrenic patients. Biol Psychiat 45: 1403-1411.

Bartha R, Williamson PC, Drost DJ, Malla A, Carr TJ, Cortese L et al (1997). Measurement of glutamate and glutamine in the medial prefrontal cortex of never-treated schizophrenic patients and healthy controls by proton magnetic resonance spectroscopy. Arch Gen Psychiat 54: 959-965.

Bernasconi A, Bernasconi N, Natsume J, Antel SB, Andermann F, Arnold DL (2003). Magnetic resonance spectroscopy and imaging of the thalamus in idiopathic generalized epilepsy. Brain 126: 2447-2454.

Bertolino A, Callicott JH, Elman I, Mattay VS, Tedeschi G, Frank JA et al (1998b). Regionally specific neuronal pathology in untreated patients with schizophrenia: a proton magnetic resonance spectroscopic imaging study. Biol Psychiat 43: 641-648.

Bertolino A, Callicott JH, Mattay VS, Weidenhammer KM, Rakow $\mathrm{R}$, Egan MF et al (2001). The effect of treatment with antipsychotic drugs on brain $N$-acetylaspartate measures in patients with schizophrenia. Biol Psychiat 49: 39-46.

Bertolino A, Callicott JH, Nawroz S, Mattay VS, Duyn JH, Tedeschi $\mathrm{G}$ et al (1998c). Reproducibility of proton magnetic resonance spectroscopic imaging in patients with schizophrenia. Neuropsychopharmacology 18: 1-9.

Bertolino A, Esposito G, Callicott JH, Mattay VS, Van Horn JD, Frank JA et al (2000). Specific relationship between prefrontal neuronal $\mathrm{N}$-acetylaspartate and activation of the working memory cortical network in schizophrenia. Am J Psychiat 157: 26-33.

Bertolino A, Kumra S, Callicott JH, Mattay VS, Lestz RM, Jacobsen $\mathrm{L}$ et al (1998a). Common pattern of cortical pathology of childhood-onset and adult-onset schizophrenia as identified by proton magnetic resonance spectroscopic imaging. $A m \mathrm{~J}$ Psychiatr 155: 1376-1383.

Bertolino A, Nawroz S, Mattay VS, Barnett AS, Duyn JH, Moonen CTW et al (1996). Regionally specific pattern of neurochemical pathology in schizophrenia as assessed by multislice proton magnetic resonance spectroscopic imaging. Am J Psychiat 153: 1554-1563.

Bertolino A, Sciota D, Brudaglio F, Altamura M, Blasi G, Bellomo A et al (2003). Working memeory deficits and levels of $\mathrm{N}$-acetylaspartate in patients with schizophreniform disorder. Am J Psychiatr 160: 483-489.

Bertolino A, Weinberger DR (1999). Proton magnetic resonance spectroscopy in schizophrenia. Eur J Radiol 30: 132-141.

Birken DL, Oldendorf WH (1989). $N$-acetyl-L-aspartic acid: a literature review of a compound prominent in ${ }^{1} \mathrm{H}-\mathrm{NMR}$ spectroscopic studies of brain. Neurosci Biobehav Rev 13: 23-31.

Block W, Bayer TA, Tepest R, Traber F, Rietschel M, Muller DJ et al (2000). Decreased frontal lobe ratio of $N$-acetyl aspartate to choline in familial schizophrenia: a proton magnetic resonance spectroscopy study. Neurosci Lett 289: 147-151.

Braus DF, Ende G, Weber-Fahr W, Demirakca T, Henn FA (2001). Favorable effect on neuronal viability in the anterior cingulate gyrus due to long-term treatment with atypical antipsychotics: an MRSI study. Pharmacopsychiatry 34: 251-253.

Braus DF, Ende G, Weber-Fahre W, Demirakca T, Tost H, Henn FA (2002). Functioning and neuronal viability of the anterior 
cingulate neurons following antipsychotic treatment: MRspectroscopic imaging in chronic schizophrenia. Eur Neuropsychopharm 12: 145-152.

Brooks WM, Hodde-Vargas J, Vargas LA, Yeo RA, Ford CC, Hendren RL (1998). Frontal lobe of children with schizophrenia spectrum disorders: a proton magnetic resonance spectroscopy study. Biol Psychiatr 43: 263-269.

Buckley PF, Moore C, Long H, Larkin C, Thompson P, Mulvany F et al (1994). ${ }^{1} \mathrm{H}$-magnetic resonance spectroscopy of the left temporal and frontal lobes in schizophrenia: clinical, neurodevelopmental, and cognitive correlates. Biol Psychiatr 36: 792-800.

Bustillo JR, Lauriello J, Rowland LM, Jung RE, Petropoulos H, Hart BL et al (2001). Effects of chronic haloperidol and clozapine treatments on frontal and caudate neurochemistry in schizophrenia. Psychiatr Res Neuroimaging 107: 135-149.

Bustillo JR, Lauriello J, Rowland LM, Thomson LM, Petropoulos H, Hammond $\mathrm{R}$ et al (2002a). Longitudinal follow-up of neurochemical changes during the first year of antipsychotic treatment in schizophrenia patients with minimal previous medication exposure. Schizophr Res 58: 313-321.

Bustillo JR, Rowland LM, Lauriello J, Petropoulos H, Hammond R, Hart B et al (2002b). High choline concentrations in the caudate nucleus in antipsychotic-naïve patients with schizophrenia. Am J Psychiatr 159: 130-133.

Callicott JH, Bertolino A, Egan MF, Mattay VS, Langheim FJP, Weinberger DR (2000). Selective relationship between prefrontal $\mathrm{N}$-acetylaspartate measures and negative symptoms in schizophrenia. Am J Psychiatr 157: 1646-1651.

Callicott JH, Egan MF, Bertolino A, Mattay VS, Langheim FJP, Frank JA et al (1998). Hippocampal $N$-acetyl aspartate in unaffected siblings of patients with schizophrenia: a possible intermediate neurobiological phenotype. Biol Psychiatr 44: 941-950.

Cecil KM, DelBello MP, Sellars MC, Strakowski SM (2003). Proton magnetic resonance spectroscopy of the frontal lobe and cerebellar vermis in children with a mood disorder and a familial risk for bipolar disorder. J Child Adolesc Psychopharmacol 13: 545-555.

Cecil KM, Lenkinski RE, Gur RE, Gur RC (1999). Proton magnetic resonance spectroscopy in the frontal and temporal lobes of neuroleptic naïve patients with schizophrenia. Neuropsychopharmacology 20: 131-140.

Choe BY, Kim K-T, Suh TS, Lee C, Paik IH, Bahk YW et al (1994). ${ }^{1} \mathrm{H}$ magnetic resonance spectroscopy characterization of neuronal dysfunction in drug-naïve, chronic schizophrenia. Acad Radiol 1: 211-216.

Choe BY, Suh TS, Shinn KS, Lee CW, Lee C, Paik IH (1996). Observation of metabolic changes in chronic schizophrenia after neuroleptic treatment by in vivo hydrogen magnetic resonance spectroscopy. Invest Radiol 31: 345-352.

de Stefano N, Matthews PM, Arnold DL (1995). Reversible decreases in $\mathrm{N}$-acetylaspartate after acute brain injury. Mag Reson Med 34: 721-727.

Deicken RF, Eliaz Y, Feiwell R, Schuff N (2001b). Increased thalamic $N$-acetylaspartate in male patients with familial bipolar I disorder. Psychiatr Res Neuroimag 106: 35-45.

Deicken RF, Feiwell R, Schuff N, Soher B (2001a). Evidence for altered cerebellar vermis neuronal integrity in schizophrenia. Psychiatr Res Neuroimagig 107: 125-134.

Deicken RF, Johnson C, Eliaz Y, Schuff N (2000). Reduced concentrations of thalamic $N$-acetylaspartate in male patients with schizophrenia. Am J Psychiatr 157: 644-647.

Deicken RF, Pegues M, Amend D (1999). Reduced hippocampal $\mathrm{N}$-acetylaspartate without volume loss in schizophrenia. Schizophr Res 37: 217-223.

Deicken RF, Zhou L, Corwin F, Vinogradov S, Weiner MW (1997b). Decreased left frontal lobe $N$-acetylaspartate in schizophrenia. Am J Psychiatr 154: 688-690.
Deicken RF, Zhou L, Schuff N, Fein G, Weiner MW (1998). Hippocampal neuronal dysfunction in schizophrenia as measured by proton magnetic resonance spectroscopy. Biol Psychiatr 43: 483-488.

Deicken RF, Zhou L, Schuff N, Weiner MW (1997a). Proton magnetic resonance spectroscopy of the anterior cingulate region in schizophrenia. Schizophr Res 27: 65-71.

Delamillieure P, Constans JM, Fernandez J, Brazo P, Benali K, Courtheoux $\mathrm{P}$ et al (2002). Proton magnetic resonance spectroscopy $\left({ }^{1} \mathrm{H}\right.$ MRS) in schizophrenia: investigation of the right and left hippocampus, thalamus, and prefrontal cortex. Schizophr Bull 28: 329-339.

Delamillieure P, Fernandez J, Constans JM, Brazo P, Benali K, Abadie $\mathrm{P}$ et al (2000). Proton magnetic resonance spectroscopy of the medial prefrontal cortex in patients with deficit schizophrenia: preliminary report. Am J Psychiatr 157: 641-643.

Dixon RM, Bradley KM, Budge MM, Styles P, Smith AD (2002). Longitudinal quantitative proton magnetic resonance spectroscopy of the hippocampus in Alzheimer's disease. Brain 125: 2332-2341.

Dowling C, Bollen AW, Noworolski SM, McDermott MW, Barbaro NM, Day MR et al (2001). Preoperative proton MR spectroscopic imaging of brain tumors and correlation with histopathologic analysis of resection specimens. Am J Neuroradiol 22: 604-612.

Eluri R, Paul C, Roemer R, Boyko O (1998). Single-voxel proton magnetic resonance spectroscopy of the pons and cerebellum in patients with schizophrenia: a preliminary study. Psychiatr Res Neuroimaging 84: 17-26.

Ende G, Braus DF, Walter S, Henn FA (2001). Lower concentration of thalamic $\mathrm{N}$-acetylaspartate in patients with schizophrenia: a replication study. Am J Psychiatr 158: 1314-1316.

Ende G, Braus DF, Walter S, Weber-Fahr W, Henn FA (2003). Multiregional ${ }^{1} \mathrm{H}-\mathrm{MRSI}$ of the hippocampus, thalamus, and basal ganglia in schizophrenia. Eur Arch Psychiatry Clin Neurosci 253: 9-15.

Ende G, Braus DF, Wlater S, Weber-Fahr W, Soher B, Maudsley AA et al (2000). Effects of age, medication, and illness duration on the $\mathrm{N}$-acetyl aspartate signal of the anterior cingulate region in schizophrenia. Schizophr Res 41: 389-395.

Fannon D, Simmons A, Tennakoon L, O'Ceallaigh S, Sumich A, Doku V et al (2003). Selective deficit of hippocampal $\mathrm{N}$ acetylaspartate in antipsychotic-naïve patients with schizophrenia. Biol Psychiatr 54: 587-598.

Fujimoto T, Nakano T, Takano T, Takeuchi K, Yamada K, Fukuzako $\mathrm{T}$ et al (1996). Proton magnetic resonance spectroscopy of basal ganglia in chronic schizophrenia. Biol Psychiatr 40: $14-18$.

Fukuzako H, Kodama S, Fukuzako T, Yamada K, Doi W, Sato D et al (1999). Subtype-associated metabolite differences in the temporal lobe in schizophrenia detected by proton magnetic resonance spectroscopy. Psychiatr Res Neuroimaging 92: 45-56.

Fukuzako H, Takeuchi K, Hokazono Y, Fukuzako T, Yamada K, Hashiguchi $\mathrm{T}$ et al (1995). Proton magnetic resonance spectroscopy of the left medial temporal and frontal lobes in chronic schizophrenia: preliminary report. Psychiatr Res Neuroimaging 61: $193-200$

Fukuzako H (2000). Heritability heightens brain metabolite differences in schizophrenia. J Neuropsychiatry Clin Neurosci 12: 95-97.

Gadea M, Martinez-Bisbal MC, Marti-Bonmati L, Espert R, Casanova R, Coret F et al (2004). Spectroscopic axonal damage to the right locus coeruleus relates to selective attention impairment in early stage relapsing-remitting multiple sclerosis. Brain 127: 89-98.

Galanaud D, Chinot O, Nicoli F, Confort-Gouny S, Le Fur Y, Barrie-Attarian $\mathrm{M}$ et al (2003). Use of proton magnetic resonance spectroscopy of the brain to differentiate gliomatosis cerebri from low-grade glioma. J Neurosurg 98: 269-276. 
Gimenez M, Junque C, perez M, Vendrell P, Baeza I, Salamero M et al (2003). Basal ganglia $N$-acetylaspartate correlates with the performance in the procedural task 'Tower of Hanoi' of neuroleptic-naïve schizophrenic patients. Neurosci Lett 347: 97-100.

Guerrini L, Lolli F, Ginestroni A, Belli G, Della Nave RD, Tessa C et al (2004). Brainstem neurodegeneration correlates with clinical dysfunction in SCA1 but not SCA2. A quantitative volumetric, diffusion and proton spectroscopy MR study. Brain 127: 1785-1795.

Hagino H, Suzuki M, Mori K, Nohara S, Yamashita I, Takahashi T et al (2002). Proton magnetic resonance spectroscopy of the inferior frontal gyrus and thalamus and its relationship to verbal learning task performance in patients with schizophrenia: a preliminary report. Psychaitr Clin Neurosci 56: 499-507.

Heimberg C, Komoroski RA, Lawson WB, Cardwell D, Karson CN (1998). Regional proton magnetic resonance spectroscopy in schizophrenia and exploration of the drug effect. Psychiatr Res Neuroimaging 83: 105-115.

Kalra S, Cashman NR, Genge A, Arnold DL (1998). Recovery of $\mathrm{N}$-acetylaspartate in corticomotor neurons of patients with ALS after riluzole therapy. Neuroreport 9: 1757-1761.

Kegeles L, Humaran TJ, Mann JJ (1998). In vivo neurochemistry of the brain in schizophrenia as revealed by magnetic resonance spectroscopy. Biol Psychiatr 44: 382-398.

Kegeles LS, Shungu DC, Anjilvel S, Chan S, Ellis SP, Xanthopoulos $\mathrm{E}$ et al (2000). Hippocampal pathology in schizophrenia: magnetic resonance imaging and spectroscopy studies. Psychiatr Res Neuroimaging 98: 163-175.

Komoroski RA, Kotrla KJ, Lemen L, Lindquist D, Diaz P, Foundas A (2004). Brain metabolite concentration ratios in vivo: multisite reproducibility by single-voxel ${ }^{1} \mathrm{H}$ MR spectroscopy. Mag Reson Imaging 22: 721-725.

Lim KO, Adalsteinsson E, Spielman D, Sullivan EV, Rosenbloom MJ, Pfefferbaum A (1998). Proton magnetic resonance spectroscopic imaging of cortical gray and white matter in schizophrenia. Arch Gen Psychiatr 55: 346-352.

Lyoo IK, Renshaw PF (2002). Magnetic resonance spectroscopy: current and future applications in psychiatric research. Biol Psychiatr 51: 195-207.

Maier M, Ron MA, Barker GJ, Tofts PS (1995). Proton magnetic resonance spectroscopy: an in vivo method of estimating hippocampal neuronal depletion in schizophrenia. Psychol Med 25: 1201-1209.

Maier M, Ron MA (1996). Hippocampal age-related changes in schizophrenia: a proton magnetic resonance spectroscopy study. Schizophr Res 22: 5-17.

Martin E, Capone A, Schneider J, Hennig J, Thiel T (2001). Absence of $\mathrm{N}$-acetylaspartate in the human brain: impact on neurospectroscopy? Ann Neurol 49: 518-521.

Mascalchi M, Belli G, Guerrini L, Nistri M, Del Sappia I, Vallari N (2002). Proton MR spectroscopy of Wernicke encephalopathy. Am J Neuroradiol 23: 1803-1806.

Matalon R, Michals K, Kaul R (1995). Canavan disease: from spongy degeneration to molecular analysis. J Pediatr 127: 511-517.

Meyerhoff DJ, MacKay S, Bachman L, Poole N, Dillon WP, Weiner MW et al (1993). Reduced brain $N$-acetyl-aspartate suggests neuronal loss in cognitively impaired human immuno-deficiency virus-seropositive individuals: in vivo ${ }^{1} \mathrm{H}$ magnetic resonance spectroscopic imaging. Neurology 43: 509-515.

Miller SP, McQuillen PS, Vigneron DB, Glidden DV, Barkovich AJ, Ferriero DM et al (2004). Preoperative brain injury in newborns with transposition of the great arteries. Ann Thorac Surg 77: 1698-1706.

Moore CM, Bonello CM, Sherwood AR, Cohen BM, Renshaw PF, Yurgulen-Todd DA (2002). Mesial temporal lobe Cho to $\mathrm{Cr}(\mathrm{PRc})$ ratio asymmetry in chronic schizophrenics. Schizophr Res 57: $35-42$.
Mullins PG, Rowland L, Bustillo J, Bedrick EJ, Lauriello J, Brooks WM (2003). Reproducibility of ${ }^{1} \mathrm{H}$-MRS measurements in schizophrenic patients. Mag Reson Med 50: 704-707.

Murphy DG, Critchley HD, Schmitz N, McAlonan G, Van Amelsvoort T, Robertson D et al (2002). Asperger syndrome: a proton magnetic resonance spectroscopy study of brain. Arch Gen Psychiatr 59: 885-891.

Nasrallah HA, Skinner TE, Schmalbrock P, Robitaille PM (1994). Proton magnetic resonance spectroscopy $\left({ }^{1} \mathrm{H}\right.$ MRS) of the hippocampal formation in schizophrenia: a pilot study. $\mathrm{Br} J$ Psychiatr 165: 481-485.

Ohara K, Isoda H, Suzuki Y, Takehara Y, Ochiai M, Takeda H et al (2000). Proton magnetic resonance spectroscopy of lenticular nuclei in simple schizophrenia. Prog Neuro-Psychopharmacol Biol Psychiatr 24: 507-519.

Omori M, Murata T, Kimura H, Koshimoto Y, Kado H, Ishimori Y et al (2000). Thalamic abnormalities in patients with schizophrenia revealed by proton magnetic resonance spectroscopy. Psychiatr Res Neuroimaging 98: 155-162.

Omori M, Pearce J, Komoroski RA, Griffin ST, Mrak RE, Husain $\mathrm{MM}$ et al (1997). In vitro ${ }^{1} \mathrm{H}$-magnetic resonance spectroscopy of postmortem brains with schizophrenia. Biol Psychiatr 42: 359-366.

O’Neill J, Levitt J, Caplan R, Asarnow R, McCracken JT, Toga AW et al (2004). ${ }^{1} \mathrm{H}$ MRSI evidence of metabolic abnormalities in childhood-onset schizophrenia. Neuroimage 21: 1781-1789.

Pavlakis SG, Kingsley PB, Harper R, Buckwald S, Spinazzola R, Frank $\mathrm{Y}$ et al (1999). Correlation of basal ganglia magnetic resonance spectroscopy with Apgar score in perinatal asphyxia. Arch Neurol 56: 1476-1481.

Renshaw PF, Yurgelun-Todd DA, Tohen M, Gruber S, Cohen BM (1995). Temporal lobe proton magnetic resonance spectroscopy of patients with first-episode psychosis. Am J Psychiatr 152: 444-446.

Richards TL (1991). Proton MR spectroscopy in multiple sclerosis: value in establishing diagnosis, monitoring progression, and evaluating therapy. Am J Roentgenol 157: 1073-1078.

Sanchez-Pernaute R, Garcia-Segura JM, del Barrio AA, Viano J, de Yebenes JG (1999). Clinical correlation of striatal ${ }^{1} \mathrm{H}$ MRS changes in Huntington's disease. Neurology 53: 806-812.

Schuff N, Capizzano AA, Du AT, Amend DL, O’Neill J, Norman D et al (2003). Different patterns of $N$-acetylaspartate loss in subcortical ischemic vascular dementia and AD. Neurology 61: 358-364.

Sharma R, Venkatasubramanian PN, Barany M, Davis JM (1992). Proton magnetic resonance spectroscopy of the brain in schizophrenic and affective patients. Schizophr Res 8: 43-49.

Shenton ME, Dickey CC, Frumin M, McCarley RW (2001). A review of MRI findings in schizophrenia. Schizophr Res 49: 1-52.

Shimizu H, Shirane R, Fujiwara S, Takahashi A, Yoshimoto T (1997). Proton magnetic resonance spectroscopy in children with moya-moya disease. Clin Neurol Neurosurg 99: S64-S67.

Shioiri T, Hamakawa H, Kato T, Murashita J, Fujii K, Inubushi T et al (1996). Proton magnetic resonance spectroscopy of the basal ganglia in patients with schizophrenia: a preliminary report. Schizophr Res 22: 19-26.

Sigmundsson T, Maier M, Toone BK, Williams SCR, Simmons A, Greenwood $\mathrm{K}$ et al (2003). Frontal lobe $N$-acetylaspartate correlates with psychopathology in schizophrenia: a proton magnetic resonance spectroscopy study. Schizophr Res 64: 63-71.

Spaniel F, Hajek T, Tintera J, Harantova P, Dezortova M, Hajek M (2003). Differences in fMRI and MRS in a monozygotic twin pair discordant for schizophrenia (case report). Acta Psychiatr Scand 107: 155-158.

Stanley JA, Williamson PC, Drost DJ, Rylett RJ, Carr TJ, Malla A et al (1996). An in vivo proton magnetic resonance spectroscopy study of schizophrenia patients. Schizophr Bull 22: 597-609. 
Steel RM, Bastin ME, McConell S, Marshall I, Cunningham-Owens DG, Lawrie SM et al (2001). Diffusion tensor imaging (DTI) and proton magnetic resonance spectroscopy $\left({ }^{1} \mathrm{H}\right.$ MRS) in schizophrenic subjects and normal controls. Psychiatr Res Neuroimaging 106: $161-170$.

Steen RG, Ogg RJ (2005). Abnormally high levels of brain $\mathrm{N}$-acetylaspartate in children with sickle cell disease. Am J Neuroradiol 26: 463-468.

Takanashi J, Inoue $\mathrm{K}$, Tomita $\mathrm{M}$, Kurihara A, Morita F, Ikehira $\mathrm{H}$ et al (2002). Brain $N$-acety-laspartate is elevated in PelizaeusMerzbacher disease with PLP1 duplication. Neurology 58: 237-241.

Tartaglia MC, Narayanan S, Francis SJ, Santos AC, De Stefano N, Lapierre $\mathrm{Y}$ et al (2004). The relationship between diffuse axonal damage and fatigue in multiple sclerosis. Arch Neurol 61: 201-207.

Taylor JS, Ogg RJ, Langston JW (1998). Proton MR spectroscopy of pediatric brain tumors. Neuroimag Clin N Am 8: 753-779.

Theberge J, Al-Semaan Y, Williamson PC, Menon RS, Neufeld RW, Rajakumar $\mathrm{N}$ et al (2003). Glutamate and glutamine in the anterior cingulate and thalamus of medicated patients with chronic schizophrenia and healthy controls measured with $4.0 \mathrm{~T}$ proton MRS. Am J Psychiatr 160: 2231-2233.

Theberge J, Bartha R, Drost DJ, Menon RS, Malla A, Takhar J et al (2002). Glutamate and glutamine measured with $4.0 \mathrm{~T}$ proton MRS in never-treated patients with schizophrenia and healthy volunteers. Am J Psychiatr 159: 1944-1946.

Thomas MA, Ke Y, Levitt J, Caplan R, Curran J, Asarnow R et al (1998). Preliminary study of frontal lobe ${ }^{1} \mathrm{H}$ MR spectroscopy in childhood-onset schizophrenia. J Magn Reson Imag 8: 841-846.
Tibbo P, Hanstock CC, Asghar S, Silverstone P, Allen PS (2000). Proton magnetic resonance spectroscopy $\left({ }^{1} \mathrm{H}-\mathrm{MRS}\right)$ of the cerebellum in men with schizophrenia. J Psychiaty Neurosci 25: 509-512.

Valenzuela MJ, Sachdev P (2001). Magnetic resonance spectroscopy in AD. Neurology 56: 592-598.

Vermathen P, Laxer KD, Schuff N, Matson GB, Weiner MW (2003). Evidence of neuronal injury outside the medial temporal lobe in temporal lobe epilepsy: $N$-acetylaspartate concentration reductions detected with multisection proton MR spectroscopic imaging-initial experience. Radiology 226: 195-202.

Vuori K, Kankaanranta L, Hakkinen AM, Gaily E, Valanne L, Granstrom ML et al (2004). Low-grade gliomas and focal cortical developmental malformations: differentiation with proton MR spectroscopy. Radiology 230: 703-708.

Weber-Fahr W, Ende G, Braus DF, Bachert P, Soher BJ, Henn FA et al (2002). A fully automated method for tissue segmentation and CSF-correction of proton MRSI metabolites corroborates abnormal hippocampal NAA in schizophrenia. Neuroimage 16: 49-60.

Yamasue H, Fukui T, Fukuda R, Yamada H, Yamasaki S, Kuroki N et al (2002). ${ }^{1} \mathrm{H}-\mathrm{MR}$ spectroscopy and gray matter volume of the anterior cingulate cortex in schizophrenia. Neuroreport 13: 2133-2137.

Yurgelun-Todd DA, Renshaw PF, Gruber SA, Waternaux C, Cohen BM (1996). Proton magnetic resonance spectroscopy of the temporal lobes in schizophrenics and normal controls. Schizophr Res 19: 55-59.

Zimmerman RA, Wang ZJ (1997). The value of proton MR spectroscopy in pediatric metabolic brain disease. $A m J$ Neuroradiol 18: 1872-1879. 